\title{
Commentary: SPG7 is an essential and conserved component of the mitochondrial permeability transition pore
}

\author{
Paolo Bernardi ${ }^{1 *}$ and Michael Forte ${ }^{2 *}$ \\ ${ }^{1}$ Department of Biomedical Sciences, University of Padova, Padova, Italy, ${ }^{2}$ Vollum Institute, Oregon Health and Science \\ University, Portland, OR, USA
}

Keywords: mitochondria, permeability transition pore, SPG7, paraplegin, cell death

\section{A commentary on}

SPG7 is an essential and conserved component of the mitochondrial permeability transition pore.

by Shanmughapriya, S., Rajan, S., Hoffman, N. E., Higgins, A. M., Tomar, D., Nemani, N., et al.

OPEN ACCESS

Edited by:

Gyorgy Hajnoczky,

Thomas Jefferson University, USA

Reviewed by:

Atan Gross,

The Weizmann Institute of Science,

Israel

Jan B. Hoek,

Thomas Jefferson University, USA

*Correspondence:

Paolo Bernardi

bernardi@bio.unipd.it;

Michael Forte

forte@ohsu.edu

Specialty section:

This article was submitted to Mitochondrial Research,

a section of the journal

Frontiers in Physiology

Received: 24 September 2015

Accepted: 22 October 2015

Published: 04 November 2015

Citation:

Bernardi P and Forte M (2015) Commentary: SPG7 is an essential and conserved component of the mitochondrial permeability transition

pore. Front. Physiol. 6:320.

doi: 10.3389/fphys.2015.00320
(2015). Mol. Cell 60, 47-62. doi: 10.1016/j.molcel.2015.08.009

SPG7 (paraplegin) is the product of the SPG7 gene, whose mutations are responsible for an autosomal recessive form of hereditary spastic paraplegia (HSP) (De Michele et al., 1998). SPG7 is a AAA-protease (Casari et al., 1998) that co-assembles with a homologous protein, AFG3L, in the inner mitochondrial membrane. These proteins associate with unidentified proteins in high molecular weight complexes of up to $900 \mathrm{kDa}$, which are aberrant in HSP patient cells (Atorino et al., 2003; Koppen et al., 2007). Loss of this complex following deletion of SPG7 causes decreased activity of respiratory complex I and increased sensitivity to reactive oxygen species (ROS); both events can be rescued by expression of SPG7 (Atorino et al., 2003). A recent paper suggests that SPG7 also serves an essential role in the formation and regulation of the mitochondrial permeability transition pore (PTP) (Shanmughapriya et al., 2015).

The PTP is an inner membrane channel that forms after a permissive load of matrix $\mathrm{Ca}^{2+}$ under conditions of oxidative stress (Bernardi, 2013; Bernardi et al., 2015). Strong evidence indicates that it derives from the F-ATP synthase, which forms channels with electrophysiological features matching those expected of the PTP in mammals (Giorgio et al., 2013; Alavian et al., 2014), yeast (Carraro et al., 2014), and Drosophila (von Stockum et al., 2015). To identify regulators of the PTP, Shanmughapriya et al. used a phenotypic screen based on the mitochondrial $\mathrm{Ca}^{2+}$ retention capacity (CRC) of digitonin-permeabilized cultured human cells after treatment with siRNAs designed to suppress translation of a set of mitochondrial proteins (Shanmughapriya et al., 2015). This assay (Murphy et al., 1996; Fontaine et al., 1998) is based on the assumption that the CRC reflects the state of the PTP in situ, i.e. its propensity to open after treatment with $\mathrm{Ca}^{2+}$ and PTP agonists. The screen identified 13 proteins whose suppression caused desensitization of the PTP to $\mathrm{Ca}^{2+}$ with an increase of the CRC. The hits included well-known modulators that do not take part in PTP formation like cyclophilin (CyP) D, the matrix receptor that mediates the PTP inhibitory effect of cyclosporin A. The Authors identified SPG7 amongst the hits, and selected it for further study because it could be co-immunoprecipitated with CyPD in a complex that also included outer membrane VDAC1 (Shanmughapriya et al., 2015). Elimination of SPG7 expression by Cas9/CRISPR methods conferred protection from $\mathrm{Ca}^{2+}$ - and oxidant-induced PTP opening and from cell death, as expected based on PTP desensitization. The Authors conclude that SPG7 is an 
essential component of the PTP complex together with VDAC1, but from analysis of the results we must conclude that this is an overinterpretation that is not supported by the experimental results presented.

First and foremost, the phenotypic screen does not allow a distinction between core PTP components from regulators. This difference-only core component of the PTP must necessarily be essential to PTP formation while regulators may only modulate PTP activity- represents important and mechanistically discrete phenomena. Indeed, failure to appreciate this critical difference has often confused our understanding of the molecular composition of the PTP. In this study, the results show that the PTP opened, albeit at higher $\mathrm{Ca}^{2+}$ loads, after suppression of all 13 transcripts including SPG7 (Shanmughapriya et al., 2015). Thus, the PTP opens even in the absence of SPG7, much as it does in the absence of CyPD (Baines et al., 2005; Basso et al., 2005; Nakagawa et al., 2005; Schinzel et al., 2005) questioning the conclusion that the protein is an essential component of the pore. Second, the mammalian PTP displays conductances up to $1.2 \mathrm{nS}$ (Szabo and Zoratti, 2014) that are unlikely to be generated by the 2-transmembrane domain proteins SPG7 and AFG3L. Indeed, and in spite of its claims, the study of Shanmughapriya et al. does not address the question of whether the putative "PTP complex" formed by SPG7, AFG3L, and VDAC1 can actually form channels at all. Thus, the graphical abstract depicting the PTP as a complex of SPG7, AFG3L, and VDAC1 is a misrepresentation of the actual findings of the paper and of the literature on the PTP. The putative role of VDAC1 deserves a specific comment.

VDAC1 is the major outer membrane protein and one of the most abundant mitochondrial proteins in mammals. Its association with the PTP was suggested based on co-purification with other putative components, i.e. the adenine nucleotide translocase and the peripheral benzodiazepine receptor, today called TSPO (McEnery et al., 1992). The link was made because

\section{REFERENCES}

Alavian, K. N., Beutner, G., Lazrove, E., Sacchetti, S., Park, H. A., Licznerski, P., et al. (2014). An uncoupling channel within the c-subunit ring of the $\mathrm{F}_{1} \mathrm{~F}_{O}$ ATP synthase is the mitochondrial permeability transition pore. Proc. Natl. Acad. Sci. U.S.A. 111, 10580-10585. doi: 10.1073/pnas.1401591111

Atorino, L., Silvestri, L., Koppen, M., Cassina, L., Ballabio, A., Marconi, R., et al. (2003). Loss of m-AAA protease in mitochondria causes complex I deficiency and increased sensitivity to oxidative stress in hereditary spastic paraplegia. J. Cell Biol. 163, 777-787. doi: 10.1083/jcb.200304112

Baines, C. P., Kaiser, R. A., Purcell, N. H., Blair, N. S., Osinska, H., Hambleton, M. A., et al. (2005). Loss of cyclophilin D reveals a critical role for mitochondrial permeability transition in cell death. Nature 434, 658-662. doi: 10.1038/nature03434

Baines, C. P., Kaiser, R. A., Sheiko, T., Craigen, W. J., and Molkentin, J. D. (2007). Voltage-dependent anion channels are dispensable for mitochondrialdependent cell death. Nat. Cell Biol. 9, 550-555. doi: 10.1038/ncb1575

Basso, E., Fante, L., Fowlkes, J., Petronilli, V., Forte, M. A., and Bernardi, P. (2005). Properties of the permeability transition pore in mitochondria devoid of cyclophilin D. J. Biol. Chem. 280, 18558-18561. doi: 10.1074/jbc.C500089200

Bernardi, P. (2013). The mitochondrial permeability transition pore: a mystery solved? Front. Physiol. 4:95. doi: 10.1016/b978-0-12-378630-2.00151-1

Bernardi, P., Rasola, A., Forte, M., and Lippe, G. (2015). The Mitochondrial permeability transition pore: channel formation by F-ATP synthase, integration ligands of TSPO are also agonists of the PTP (Kinnally et al., 1993). As shown by experiments on mitochondria from mice where the corresponding genes were deleted, neither TSPO (Šileikyte et al., 2014) nor VDAC1 (Krauskopf et al., 2006) is an essential component of the PTP or a regulator of its activity, and the effects of "TSPO ligands" on the pore could rather be explained by their interaction with the F-ATP synthase (Cleary et al., 2007; Giorgio et al., 2013). Of note, also genetic inactivation of the less abundant VDAC2 and VDAC3 isoforms does not affect PTP opening and PTP-dependent cell death (Baines et al., 2007). Thus, the reported co-immunoprecipitation of SPG7 with VDAC1 (Shanmughapriya et al., 2015) does not bear on the nature or regulation of the PTP. Our comment does not imply that the outer mitochondrial membrane does not regulate PTP activity, as discussed in detail (Bernardi et al., 2015).

Surprisingly, Shanmughapriya et al. do not discuss possible mechanisms through which SPG7 may regulate the PTP. We suspect that the high molecular weight complex formed by SPG7 and AFG3L reported by Casari and coworkers (Atorino et al., 2003; Koppen et al., 2007) may be due to a direct interaction of the AAA-protease heterodimers with F-ATP synthase, which may in turn stabilize dimers/oligomers of the complex and thus favor $\mathrm{Ca}^{2+}$-dependent PTP formation (Bernardi et al., 2015). Increased oxidative stress due to inhibition of complex I could easily explain sensitization of the PTP. Thus, SPG7 could be one more of the many regulators of the PTP, but not an essential component of the pore.

\section{ACKNOWLEDGMENTS}

Research in our laboratories is supported by Telethon (GGP14037 and GPP14187), AIRC (IG13392), Ministry of the University and Research, Italy and NIH-PHS, USA (R01GM069883 and 03DA033978-01). in signal transduction, and role in pathophysiology. Physiol. Rev. 95, 1111-1155. doi: 10.1152/physrev.00001.2015

Carraro, M., Giorgio, V., Šileikyte, J., Sartori, G., Forte, M., Lippe, G., et al. (2014). Channel formation by Yeast F-ATP synthase and the role of dimerization in the mitochondrial permeability transition. J. Biol. Chem. 289, 15980-15985. doi: 10.1074/jbc.C114.559633

Casari, G., De Fusco, M., Ciarmatori, S., Zeviani, M., Mora, M., Fernandez, P., et al. (1998). Spastic paraplegia and OXPHOS impairment caused by mutations in paraplegin, a nuclear-encoded mitochondrial metalloprotease. Cell 93, 973-983. doi: 10.1016/S0092-8674(00)81203-9

Cleary, J., Johnson, K. M., Opipari, A. W. Jr., and Glick, G. D. (2007). Inhibition of the mitochondrial $\mathrm{F}_{1} \mathrm{~F}_{0}$-ATPase by ligands of the peripheral benzodiazepine receptor. Bioorg. Med Chem. Lett. 17, 1667-1670. doi: 10.1016/j.bmcl.2006.12.102

De Michele, G., De Fusco, M., Cavalcanti, F., Filla, A., Marconi, R., Volpe, G., et al. (1998). A new locus for autosomal recessive hereditary spastic paraplegia maps to chromosome 16q24.3. Am. J. Hum. Genet. 63, 135-139. doi: 10.1086/301930

Fontaine, E., Ichas, F., and Bernardi, P. (1998). A ubiquinone-binding site regulates the mitochondrial permeability transition pore. J. Biol. Chem. 273, 25734-25740. doi: 10.1074/jbc.273.40.25734

Giorgio, V., von Stockum, S., Antoniel, M., Fabbro, A., Fogolari, F., Forte, M., et al. (2013). Dimers of mitochondrial ATP synthase form the permeability transition pore. Proc. Natl. Acad. Sci. U.S.A. 110, 5887-5892. doi: $10.1073 /$ pnas. 1217823110 
Kinnally, K. W., Zorov, D. B., Antonenko, Y. N., Snyder, S. H., McEnery, M. W., and Tedeschi, H. (1993). Mitochondrial benzodiazepine receptor linked to inner membrane ion channels by nanomolar actions of ligands. Proc. Natl. Acad. Sci. U.S.A. 90, 1374-1378. doi: 10.1073/pnas.90.4.1374

Koppen, M., Metodiev, M. D., Casari, G., Rugarli, E. I., and Langer, T. (2007). Variable and tissue-specific subunit composition of mitochondrial m-AAA protease complexes linked to hereditary spastic paraplegia. Mol. Cell Biol. 27, 758-767. doi: 10.1128/MCB.01470-06

Krauskopf, A., Eriksson, O., Craigen, W. J., Forte, M. A., and Bernardi, P. (2006). Properties of the permeability transition in $V D A C 1^{-1-}$ mitochondria. Biochim. Biophys. Acta 1757, 590-595. doi: 10.1016/j.bbabio.2006.02.007

McEnery, M. W., Snowman, A. M., Trifiletti, R. R., and Snyder, S. H. (1992). Isolation of the mitochondrial benzodiazepine receptor: association with the voltage-dependent anion channel and the adenine nucleotide carrier. Proc. Natl. Acad. Sci. U.S.A. 89, 3170-3174. doi: 10.1073/pnas.89.8.3170

Murphy, A. N., Bredesen, D. E., Cortopassi, G., Wang, E., and Fiskum, G. (1996). Bcl-2 potentiates the maximal calcium uptake capacity of neural cell mitochondria. Proc. Natl. Acad. Sci. U.S.A. 93, 9893-9898. doi: 10.1073/pnas.93.18.9893

Nakagawa, T., Shimizu, S., Watanabe, T., Yamaguchi, O., Otsu, K., Yamagata, H., et al. (2005). Cyclophilin D-dependent mitochondrial permeability transition regulates some necrotic but not apoptotic cell death. Nature 434, 652-658. doi: 10.1038 /nature 03317

Schinzel, A. C., Takeuchi, O., Huang, Z., Fisher, J. K., Zhou, Z., Rubens, J., et al. (2005). Cyclophilin D is a component of mitochondrial permeability transition and mediates neuronal cell death after focal cerebral ischemia. Proc. Natl. Acad. Sci. U.S.A. 102, 12005-12010. doi: 10.1073/pnas.0505294102
Shanmughapriya, S., Rajan, S., Hoffman, N. E., Higgins, A. M., Tomar, D. Nemani, N., et al. (2015). SPG7 is an essential and conserved component of the mitochondrial permeability transition pore. Mol. Cell 60, 47-62. doi: 10.1016/j.molcel.2015.08.009

Šileikyte, J., Blachly-Dyson, E., Sewell, R., Carpi, A., Menabò, R., Di Lisa, F., et al. (2014). Regulation of the mitochondrial permeability transition pore by the outer membrane does not involve the peripheral benzodiazepine receptor (translocator protein of $18 \mathrm{kDa}$ (TSPO)). J. Biol. Chem. 289, 13769-13781. doi: 10.1074/jbc.M114.549634

Szabo, I., and Zoratti, M. (2014). Mitochondrial channels: ion fluxes and more. Physiol. Rev. 94, 519-608. doi: 10.1152/physrev.00021.2013

von Stockum, S., Giorgio, V., Trevisan, E., Lippe, G., Glick, G. D., Forte, M. A., et al. (2015). F-ATPase of D. melanogaster Forms 53 Picosiemen (53-pS) channels responsible for Mitochondrial $\mathrm{Ca}^{2+}$-induced $\mathrm{Ca}^{2+}$ Release. J. Biol. Chem. 290, 4537-4544. doi: 10.1074/jbc.C114. 629766

Conflict of Interest Statement: The authors declare that the research was conducted in the absence of any commercial or financial relationships that could be construed as a potential conflict of interest.

Copyright $\odot 2015$ Bernardi and Forte. This is an open-access article distributed under the terms of the Creative Commons Attribution License (CC BY). The use, distribution or reproduction in other forums is permitted, provided the original author(s) or licensor are credited and that the original publication in this journal is cited, in accordance with accepted academic practice. No use, distribution or reproduction is permitted which does not comply with these terms. 